\title{
Wither the Concepts of Mole and Concentration: Conceptual Confusion in Applying $\mathbf{M}_{1} \mathrm{~V}_{1}=\mathbf{M}_{2} \mathbf{V}_{2}$
}

\author{
Sheau Huey Chong \\ Faculty of Applied Sciences and Computing, Tunku Abdul Rahman University College, Malaysia
}

Copyright $\bigcirc 2016$ by authors, all rights reserved. Authors agree that this article remains permanently open access under the terms of the Creative Commons Attribution License 4.0 International License

\begin{abstract}
Concentration of solutions problems are among the most important and at the same time one of the most challenging topics in chemistry. The aim of this study was to determine the sources of the difficulty that students often face when performing calculations related to concentration. The study involved 153 tertiary college students (food science, chemistry and biology majors) who have learned the concepts of mole and concentration of solutions prior to the study. Students' written working steps in answering two concentration questions in the semester summative examination were analyzed. The results showed that $52 \%$ of students answered Question 1 correctly whereas only $28 \%$ of students solved Question 2 successfully with a clear display of conceptual understanding. Analysis of students' answers led to the identification of common errors, in conceptual understanding of the topics. It was revealed that one contributing factor to the poor success rate in solving problems related to the concentration was the superficial understanding of the mole concept. Mastery of the mole concept is foundational to understanding concentration of solutions. Difficulties with the former may inhibit learning of the latter. However, the results of this study implied that inappropriate application of the formula $\mathrm{M}_{1} \mathrm{~V}_{1}=\mathrm{M}_{2} \mathrm{~V}_{2}$ was the main problem students faced in solving the questions. Specifically, students faced difficulties understanding the use and the meaning of $\mathrm{M}_{1} \mathrm{~V}_{1}=\mathrm{M}_{2} \mathrm{~V}_{2}$. A lack of conceptual understanding of the mole concept appeared to lead students to rely on the use of memorized formulae and steps to solve the questions. Implications for assessment, research and instruction are also included.
\end{abstract}

Keywords Molarity, $\mathrm{M}\left(\mathrm{mol} \mathrm{dm}^{-3}\right) \times$ Volume of a Solution, $\mathrm{V}\left(\mathrm{dm}^{3}\right)=$ Amount of Substance (Mole as a Unit)

\section{Introduction}

Stoichiometry problem solving is an area which poses a great challenge to students in chemistry learning. The difficulties may due to the capabilities of human learning and the abstract nature of the subject [6]. Besides, chemistry educators and chemistry textbooks often present chemistry knowledge over at least three levels of representation (i.e. macroscopic, submicroscopic, and symbolic) for which Johnstone [7] claimed that this offered too much complexity for the beginning chemistry students. For example, for an aqueous solution of sodium chloride, the macroscopic representations refer to what can be seen. The submiscroscopic illustrates a particle model with invisible particles dispersed in all directions of the solution. The symbolic shows the chemical formula, $\mathrm{NaCl}$. Nyachwaya et al [8] reported that competence in algorithmic problem solving did not translate to competence in conceptual understanding. If this fundamental 'levels of representation' is not understood, it may inhibit learning of more advanced topics such as solution concentration. The mole concept (amount of substance) is a concept that connects the macro-world with the micro-world. Mastery of this concept is of utmost importance as it equips students to learn the solution concentration topic with ease. However, many students treat the mole concept and the concentration of solutions as separate entities and their knowledge in these areas are always compartmentalized. This makes the process of learning and teaching challenging.

Numerous studies exist in chemistry education literature that deals with students' learning difficulties, alternative conceptions and problem solving strategies in the mole concept. For example, Ault [1] claimed that teaching of stoichiometry has focused on the symbolic level of representation relying heavily on algorithms which does not promote conceptual understanding. Staver et al [9] stated that students have the following two deficiencies: (a) incapacity to navigate meaning between the macro level and the sub-micro level when solving problems; and (b) insufficient understanding of the concepts and rote use of algorithms and rules. Furio et al [5] found that the conventional instruction of several chemistry courses in secondary education does not result in the students relating the idea of "amount of substance" with counting particles. Instead, they identified the "amount of substance" with mass and occasionally, with volume. 
Meanwhile, Duncan et al [4] reported that students faced difficulties when the stoichiometric proportion in a reaction was not 1:1. This led to another challenge where students deal with solutions, because they did not consider that in diluting the aqueous solution of a substance, the volume of the solution changes. Research done by Devetak, et al [3] highlighted difficulties faced by students in solving problems related to the concentration of solutions. A study carried out by de Berg [2] revealed that first-year university chemistry students performed better when the problems of sugar concentration in aqueous solutions were presented in verbal mode than in visual submicroscopic form. This shows that students probably are able to solve chemistry problems using memorized algorithms without conceptual understanding.

Previous studies have shown how difficult the topic of solutions proves to be across all levels of education. While various studies have been carried out regarding students' conceptions and understanding of the mole concept and the concentration of solutions, there is a lack of explicit investigation linking both concepts. Formula $\mathrm{M}_{1} \mathrm{~V}_{1}=\mathrm{M}_{2} \mathrm{~V}_{2}$, which combines both the mole concept and the concentration of solutions is commonly used in chemistry calculations. Factors such as conceptual understanding and problem solving skills contribute to students' performance in calculating problems related to the concentration of solutions. It is an observation of the author that current college students display an inadequate understanding of the mole concept and concentration which always leads to the inappropriate use of the formula. As such, the aim of this research was to examine college students' written calculations (working steps) when trying to solve problems related to the concentration of solutions.

\section{Method}

This study is part of a larger research project in which the author plans to develop and implement strategies in teaching the concentration of solutions to enhance students' understanding. 153 students (18-19 years old) from a private college university in Malaysia participated in the study. The number of students according to the various programmes offered at the institution is shown in Table 1.
Table 1. Number of students according to programmes.

\begin{tabular}{|c|c|}
\hline Programme & No of students \\
\hline $\begin{array}{c}\text { Bachelor of Science (Hons) in Food Science } \\
\text { (first year) }\end{array}$ & 15 \\
\hline Diploma in Food Science (second year) & 32 \\
\hline Diploma in Food Science (first year) & 56 \\
\hline $\begin{array}{c}\text { Diploma in Science (Chemistry and Biology) } \\
\text { (first year) }\end{array}$ & 50 \\
\hline Total: & 153 \\
\hline
\end{tabular}

Students from all programmes have learned the mole concept and the concentration of solutions in the prior to the study. In this study, students' working steps in solving two concentration questions as shown in Table 2 in the semester summative examination were analyzed. In the present phase of this study, quantitative analysis was intended to gauge the prevalence of certain thought patterns and not to make generalization of the findings. All answers obtained were examined and categorized by the same researcher and reviewed by two senior lecturers to ensure consistency.

Table 2. Questions used in the study

Question 1:
What is the resulting concentration when $3.5 \mathrm{~L}$ of $6.0 \mathrm{~mol} \mathrm{dm}^{-3} \mathrm{HNO}_{3}$
is added to $2.5 \mathrm{~L}$ of $1.5 \mathrm{~mol} \mathrm{dm} \mathrm{dm}^{-3} \mathrm{HNO}_{3}$ ? (Assume the final volume to
be exact $6.0 \mathrm{~L}$ )
Question 2:
Amines, $R \mathrm{NH}_{2}$, which is commonly found in bananas, grapes and
lemonsreact with picric acid to form amine picrates, which absorb
strongly at $359 \mathrm{~nm}$ (molar absorptivity $=1.25 \times 10^{4} \mathrm{~cm}^{-1} \mathrm{~mol}^{-1} \mathrm{~L}$ ). An
unknown amine $(0.1155 \mathrm{~g}$ ) is dissolved in water and diluted to 100
$\mathrm{mL}$. A 1-mL aliquot of this is diluted to $250 \mathrm{~mL}$ for measurement. If
this final solution exhibits an absorbance of 0.454 at $359 \mathrm{~nm}$ using
a $1.00-\mathrm{cm}$ cell, what is the formula weight of the amine?

\section{Results}

$52 \%$ of students answered Question 1 correctly whereas only $28 \%$ of students solved Question 2 successfully with a clear display of conceptual understanding. Examples of students' answers are shown on Figure 1 and Figure 2. The distribution of the percentage of errors of participants is summarized in Table 3. 


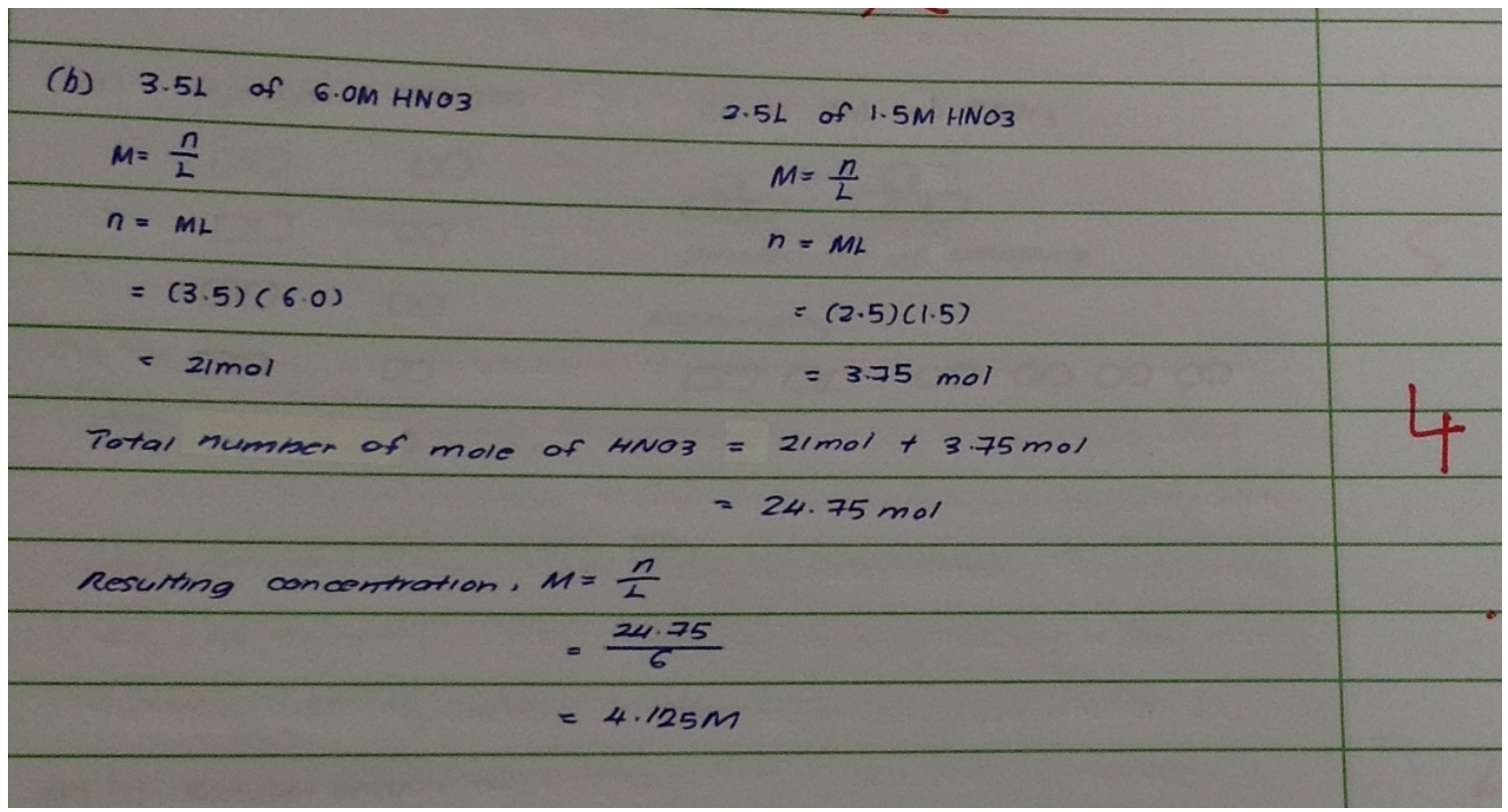

Figure 1. Example of correct answer with clear display of understanding (Question 1).

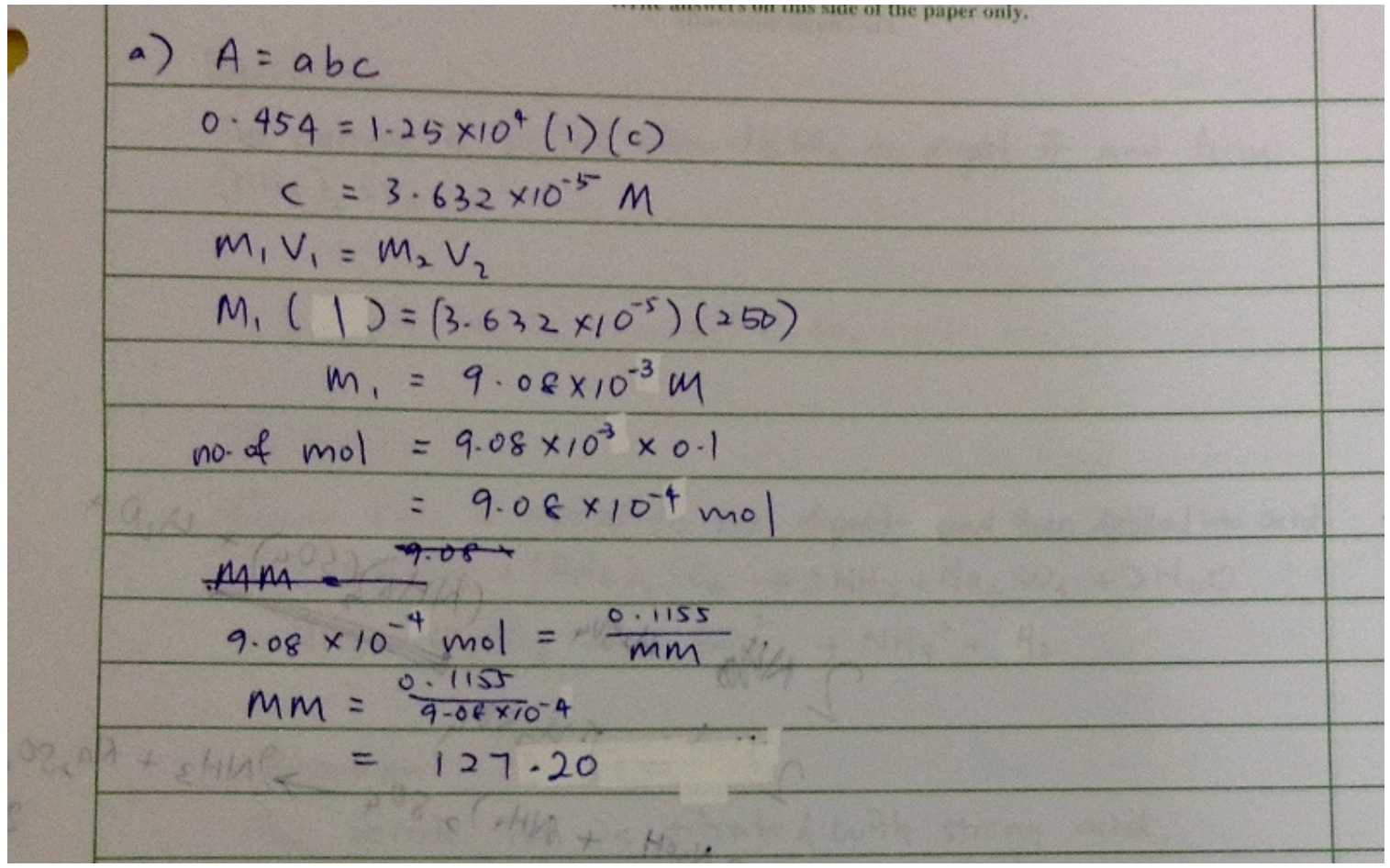

Figure 2. Example of correct answer with clear display of understanding (Question 2).

Table 3. Distribution of the Percentage of Alternative Conceptions of Participants.

\begin{tabular}{|c|c|c|}
\hline Alternative Conceptions in Question & Alternative Conceptions (Question 1) & Alternative Conceptions (Question 2) \\
\hline $\begin{array}{c}\text { Inappropriate substitution (due to } \\
\text { conceptual errors) to } \\
\mathrm{M}_{1} \mathrm{~V}_{1}=\mathrm{M}_{2} \mathrm{~V}_{2}\end{array}$ & $42.4 \%$ & $57.4 \%$ \\
\hline Mathematical error & - & $2.1 \%$ \\
\hline Did not attempt question & $5.6 \%$ & $10.6 \%$ \\
\hline Applied wrong formula & - & $2.1 \%$ \\
\hline
\end{tabular}




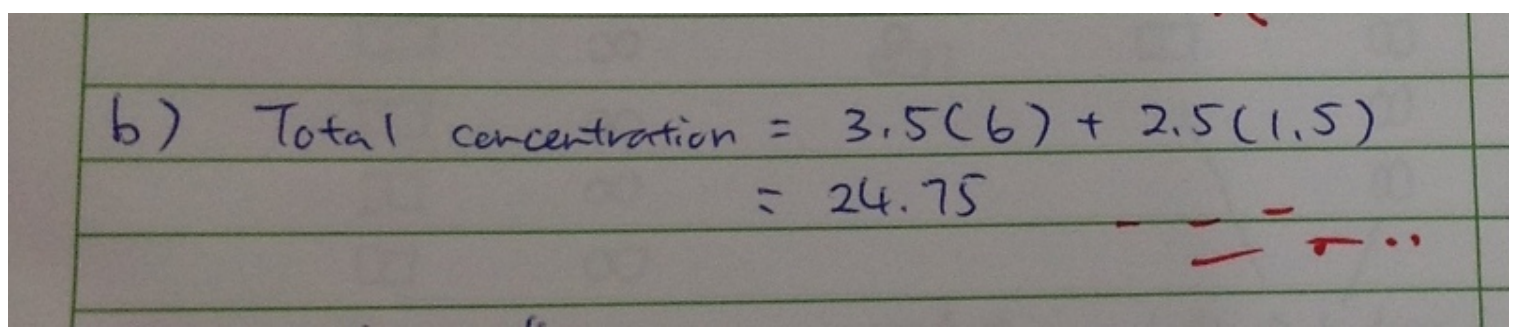

Figure 3. Example of an inappropriate substitution to $\mathrm{M}_{1} \mathrm{~V}_{1}=\mathrm{M}_{2} \mathrm{~V}_{2}$ (Question 1).

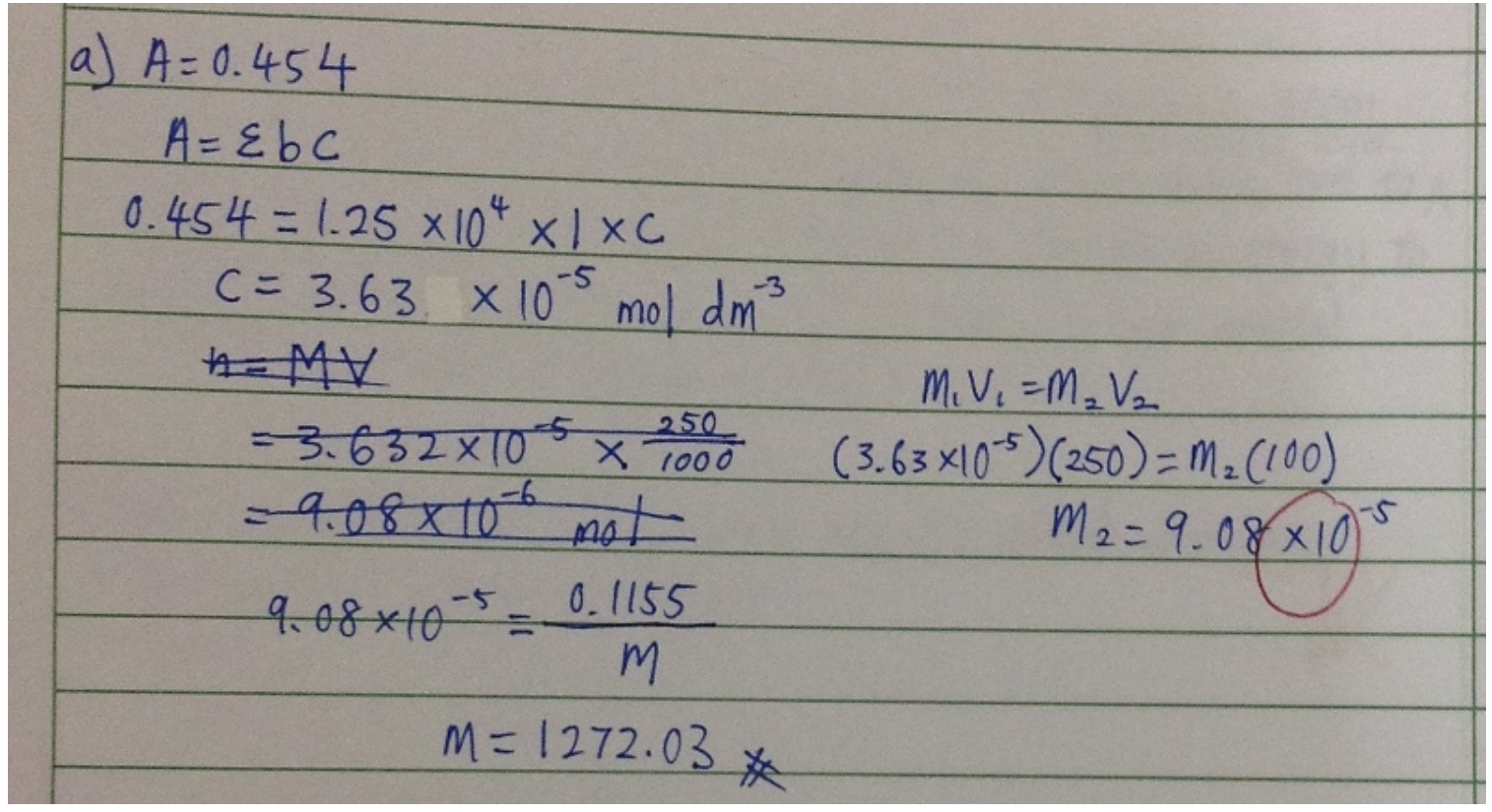

Figure 4. Example of an inappropriate substitution to $\mathrm{M}_{1} \mathrm{~V}_{1}=\mathrm{M}_{2} \mathrm{~V}_{2}$ (Question 2).

\section{Discussion and Conclusion}

From the analysis, the main conceptual error faced by the students was lack of understanding of $\mathrm{M}_{1} \mathrm{~V}_{1}=\mathrm{M}_{2} \mathrm{~V}_{2}$. The most common error among students was the incorrect values substituted in $\mathrm{M}_{1} \mathrm{~V}_{1}=\mathrm{M}_{2} \mathrm{~V}_{2}$. (See Figure 3 and Figure 4).Students' answer showed that their understanding of this formula was lacking. They could not comprehend the meaning of " $="$ in the formula. As a result, many students substituted wrong values into the formula. Students were confused between the number of moles and concentration. Although there were students who appeared to understand that $\mathrm{M}_{1} \mathrm{~V}_{1}=$ amount of substance (mole), $\mathrm{M}$ as concentration (molarity) and $\mathrm{V}$ as volume of the solution $\left(\mathrm{dm}^{3}\right)$, the analysis of the results revealed that students' understanding of $\mathrm{M}_{1} \mathrm{~V}_{1}=\mathrm{M}_{2} \mathrm{~V}_{2}$ was lacking when dilution concept was included in the questions. This study may provide awareness about conceptual problems faced by students of the mole concept in general and $\mathrm{M}_{1} \mathrm{~V}_{1}=\mathrm{M}_{2} \mathrm{~V}_{2}$ in particular. The result suggests that conceptual confusion in using $\mathrm{M}_{1} \mathrm{~V}_{1}=\mathrm{M}_{2} \mathrm{~V}_{2}$ is one of the primary factors behind students' poor success rate in calculations related to the concentration of solutions. Thus, educators perhaps could work on developing teaching strategies that help students address this problem.

\section{REFERENCES}

[1] Ault A. What's wrong with cookbooks?. J Chem Educ. 2002; 79(10):1177.

[2] de Berg K. A study of first-year chemistry students' understanding of solution concentration at the tertiary level. Chem Educ Res Pract. 2012; 13(1):8-16.

[3] Devetak I, Vogrinc J, Glažar S. Assessing 16-year-old students' understanding of aqueous solution at submicroscopic level. Res Sci Educ. 2008; 39(2):157-179.

[4] Duncan I, Johnstone A. The mole concept. Education In Chemistry. 1973; 10(6):213-214.

[5] Furió C, Azcona R, Guisasola J, Ratcliffe M. Difficulties in teaching the concepts of 'amount of substance' and 'mole'. International Journal of Science Education. 2000; 22(12):1285-1304.

[6] Johnstone A. Teaching of chemistry: Logical or psychological?. Chem Educ Res Pract. 2000; 1(1):9-15.

[7] Johnstone A. Why is science difficult to learn? Things are seldom what they seem. J Comp Assist Learn. 1991; 7(2):75-83. 
[8] Nyachwaya J, Warfa A, Roehrig G, Schneider J. College chemistry students' use of memorized algorithms in chemical reactions. Chem Educ Res Pract. 2014; 15(1):81-93.
[9] Staver J, Lumpe A. Two investigations of students' understanding of the mole concept and its use in problem solving. J Res Sci Teach. 1995; 32(2):177-193. 